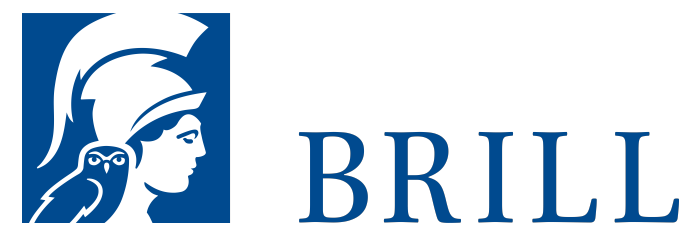

\title{
Die Zeit der Evidenz und ihr Ende
}

Lichtenbergs Schreibszene

Author: Rüdiger Campe

Im Mittelpunkt der Studie steht die Rekonstruktion des Schreibverfahrens in Lichtenbergs Sudelbüchern, in denen der Physiker, Philosoph und Literat von 1765 bis zu seinem Tod 1799

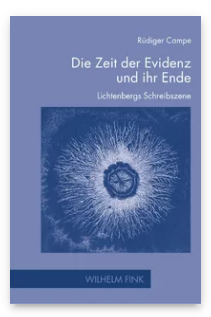

Published: 30 Notizen verschiedenster Art zusammentrug. Das „Buch, in das ich alles eintrage", wird Schauplatz einer Evidenzerzeugung, wie sie zwischen Descartes und Kant Programm war. Im Schreibverfahren Lichtenbergs erreicht die Zeit der Evidenz einen Höhepunkt, sie stößt aber auch an ihre Grenze. Ältere Arbeiten Campes sind in diesem Buch mit neuen zu einer in sich geschlossenen Studie zusammengefügt. Das methodische Konzept der "Schreibszene“, mit dem Autorschaft und Kreativität in Wissenschaft und Literatur neu zu durchdenken sind, wird an literarischen Aufsätzen und Experimentalberichten erprobt. Im Fokus stehen aber Lichtenbergs Sudelbücher: Hier ist exemplarisch zu beobachten, wie etwas, das wohl nie als Werk geplant war, für uns heute aber Lichtenbergs wichtigstes Werk darstellt, Gestalt annimmt.

Mar 2024

Subjects:

German,

Literature and

Cultural Studies

Publisher: Brill |

Fink

Series:

Zur Genealogie des Schreibens,

Volume: 25

E-Book (PDF)

ISBN: $978-3^{-}$

8467-6444-2

Paperback

ISBN: $978-3^{-}$

7705-6444-6 
Rüdiger Campe arbeitet an der Yale University, USA, wo er Alfred C. and Martha F. Mohr Professor of German und Professor of Comparative Literature ist.

Please send your order to: Brockhaus/Commission

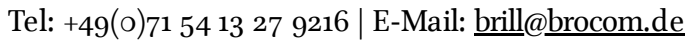

For questions please contact: Brill Deutschland GmbH

Wollmarktstraße 115 | 33098 Paderborn | Germany

Tel: +49 (o)5251 69975 o | E-Mail: sales@brill.com. 